\title{
Morning glory syndrome and the role of 3rd oct in its management
}

\begin{abstract}
Congenital optic disc anomalies that can significantly impair visual function include excavation of the optic disc and optic nerve hypoplasia. Optic disc excavations include Optic disc coloboma, Morning Glory Syndrome (MGS), Peripapillary staphyloma and Optic disc pit. We describe A case of a 70 year old lady with MGS, and the role of 3D Optical coherence tomography (OCT) in the management of MGS.
\end{abstract}

Keywords: morning glory syndrome, optical computerized tomography, retinal detachment
Volume I Issue 3 - 2014

\author{
Paul R, Kulshrestha M, Shanmugalingam S, Barr \\ D \\ Aberystwyth Eye Centre, UK
}

Correspondence: : Paul R, Aberystwyth Eye Centre, Hywel Dda University Health Board, North Road, Aberystwyth SY23 2EG, UK, Tel 07432847867,Email rajanpaul55@hotmail.com

Received: September 30, 2014 | Published: November 06, 2014
Abbreviations: MGS, morning glory syndrome; OCT, optical computerized tomography; CA, carcinoma; BCVA, best corrected visual acuity; RAPD, relative afferent pupillary defect; IOP, intra ocular pressure; RE, right eye; LE, left eye

\section{Introduction}

MGS is an uncommon congenital optic disc anomaly, which was first described by Kindler. ${ }^{1}$ It is characterized by an enlarged funnel-shaped dysplastic disc with glial tissue. The retinal vessels are increased in number, appear to arise from the disc edge and run an abnormally straight course over the peripapillary retina. ${ }^{2,3}$ Retinal detachment may occur in about one-third of cases of MGS. ${ }^{4,5}$ The retinal detachments can be associated with slit-like retinal break at the edge of the excavated anomalous $\operatorname{disc}^{6}$ or a retinal hole in tissue lying within the optic cup. ${ }^{7-9}$ These provide a fluid pathway between the vitreous cavity and the subretinal space. In such a situation an OCT especially 3D is highly beneficial. ${ }^{9-11}$ In this case the 3D OCT of the anomalous disc confirmed there were no predisposing factors for a retinal detachment and the patient was not at risk of developing retinal detachment.

\section{Case presentation}

A 70 years old lady was referred to the Aberystwyth Eye Centre for a suspicious Left optic disc and a reduced visual acuity in the left eye which did not improve with refraction. There was no significant past ocular history. She had been treated in the past for a Grade III CA Breast with radiotherapy, debulking and chemotherapy. She was not on any medications and did not have a family history of glaucoma, hereditary retinal or optic nerve anomalies.

\section{Examination}

On examination her BCVA were (Figure 1) RE: 6/5+2 and (Figure 2) LE: 6/9-3, her extraocular movements were normal. There were no phorias or tropias and there was no nystagmus. Her colour vision tested with Ishihara's colour plates was normal. The anterior segments were unremarkable and there was no RAPD. Intra ocular pressures were RE: $16 \mathrm{~mm} \mathrm{Hg}$ and LE $18 \mathrm{~mm} \mathrm{Hg}$.

\section{Fundus}

RE: Normal (Figures 1\&3).

LE: The left optic disc showed peripapillary atrophy and pigment clumping; corresponding to an enlarged blind spot there is anomalous branching of the central retinal vessels and mild elevation of the optic disc rim tissue. The retinal vessels are increased in number and tend to run to the peripheral retina in a straighter course than normal (Figures $2,4 \& 5)$.

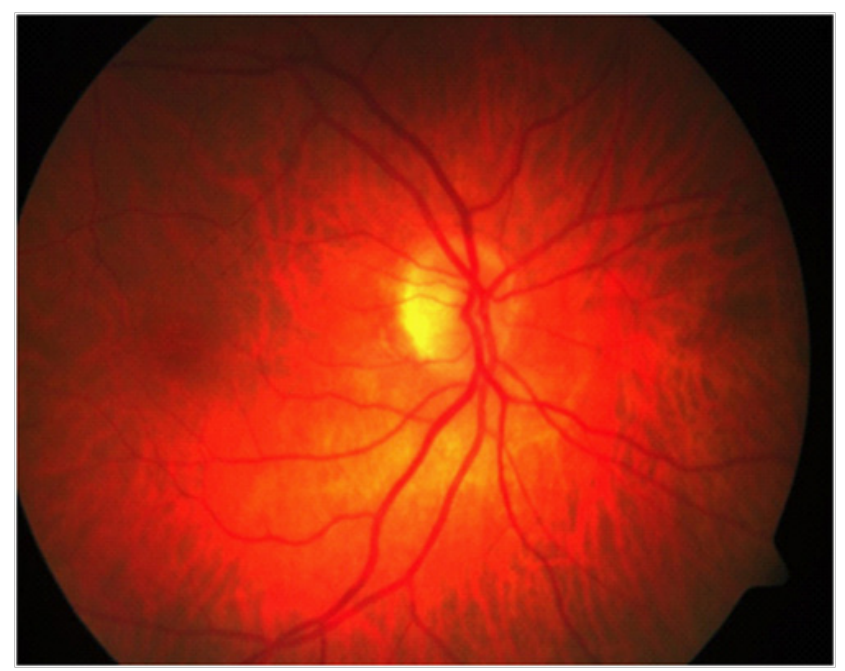

Figure I Right eye, Disc Appearance.

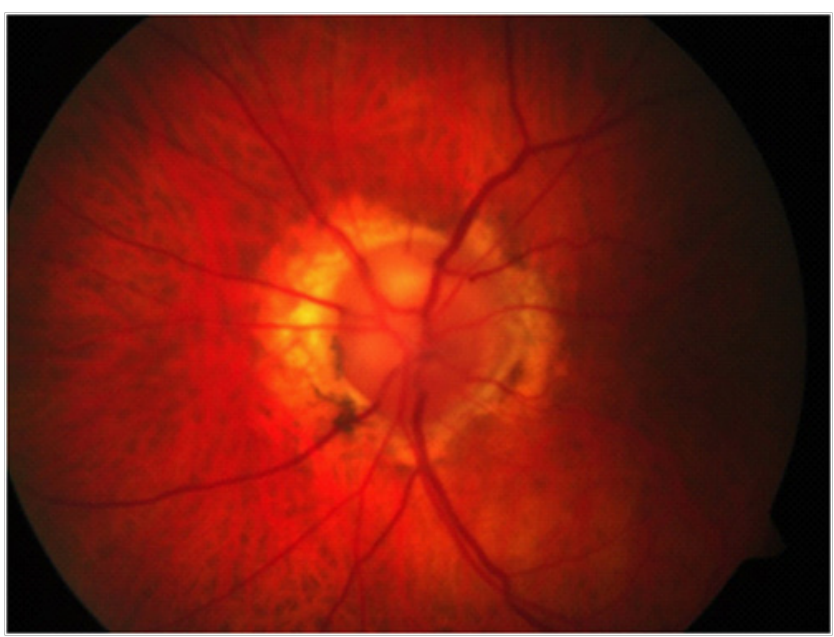

Figure 2 Left Eye. 


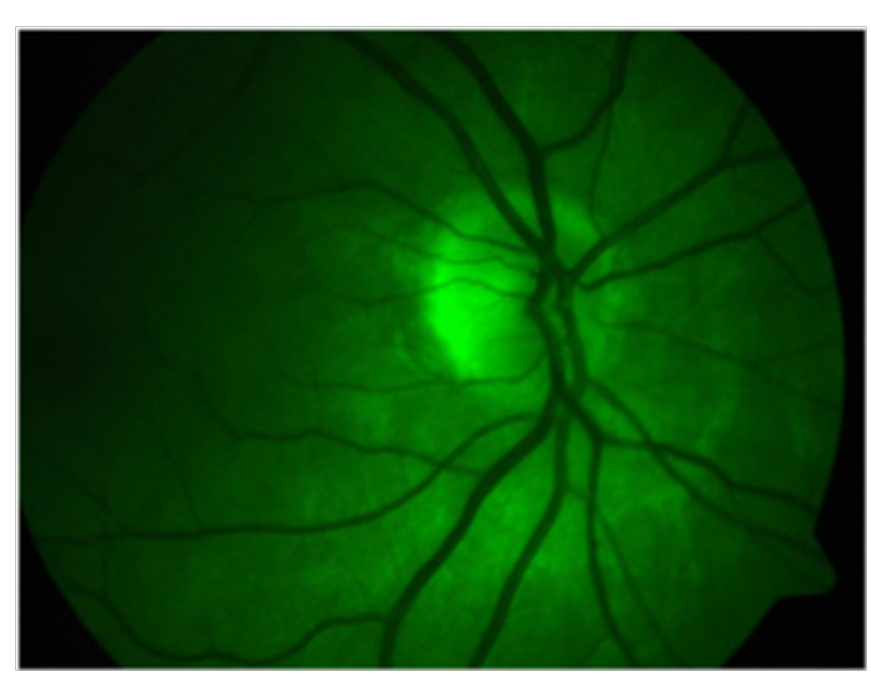

Figure 3 Right eye. Red Free Fundus Photographs.

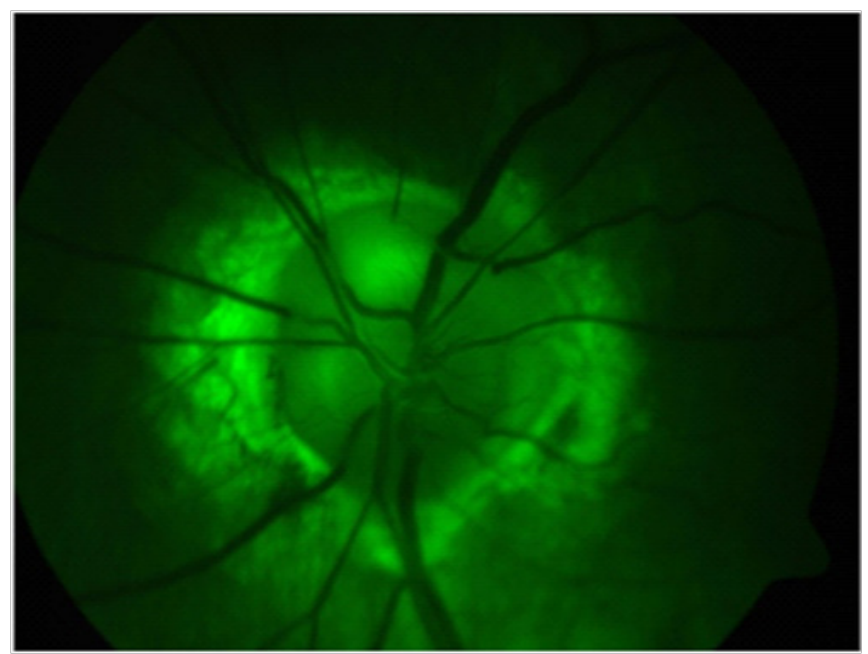

Figure 4 Left eye.

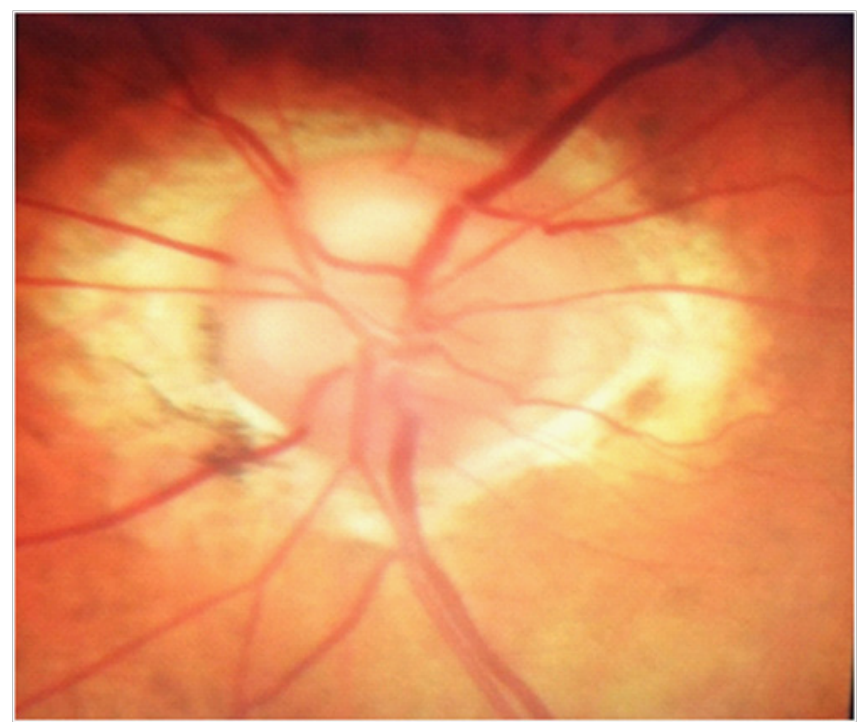

Figure 5 Left Disc: Magnified view

\section{Investigations}

Humphrey's Visual Fields revealed an enlarged Blind spot in the left eye (Figures $6 \& 7$ ).

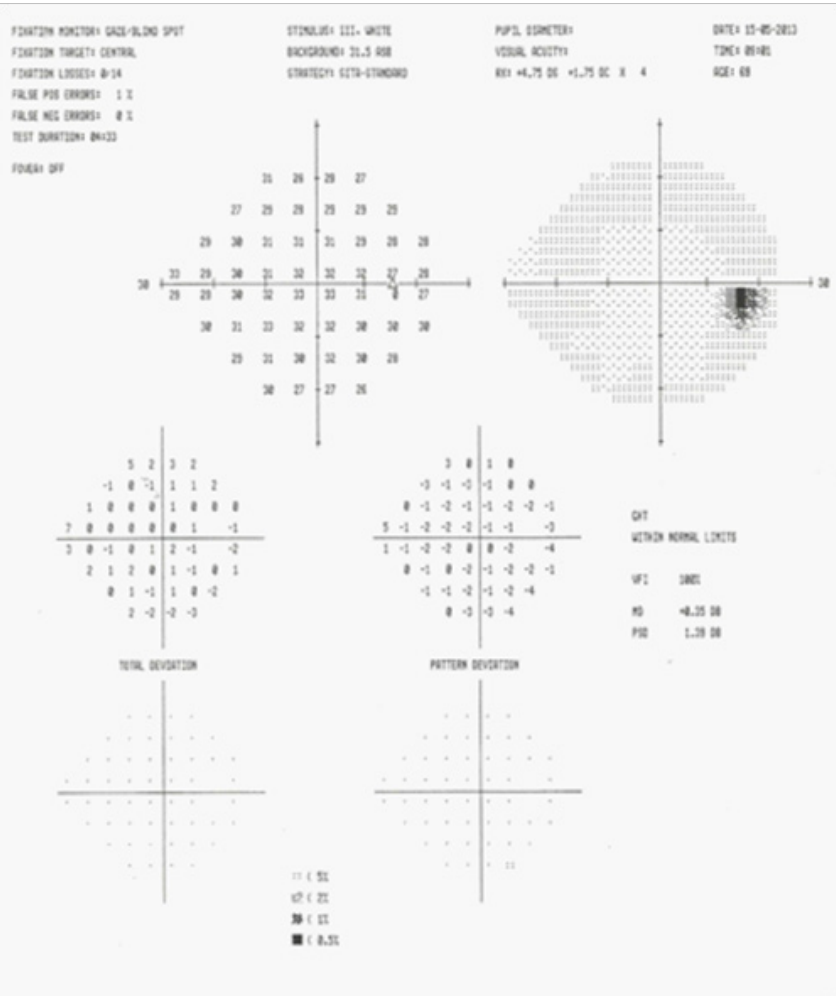

Figure 6 Right Eye. Humphrey's Visual Fields

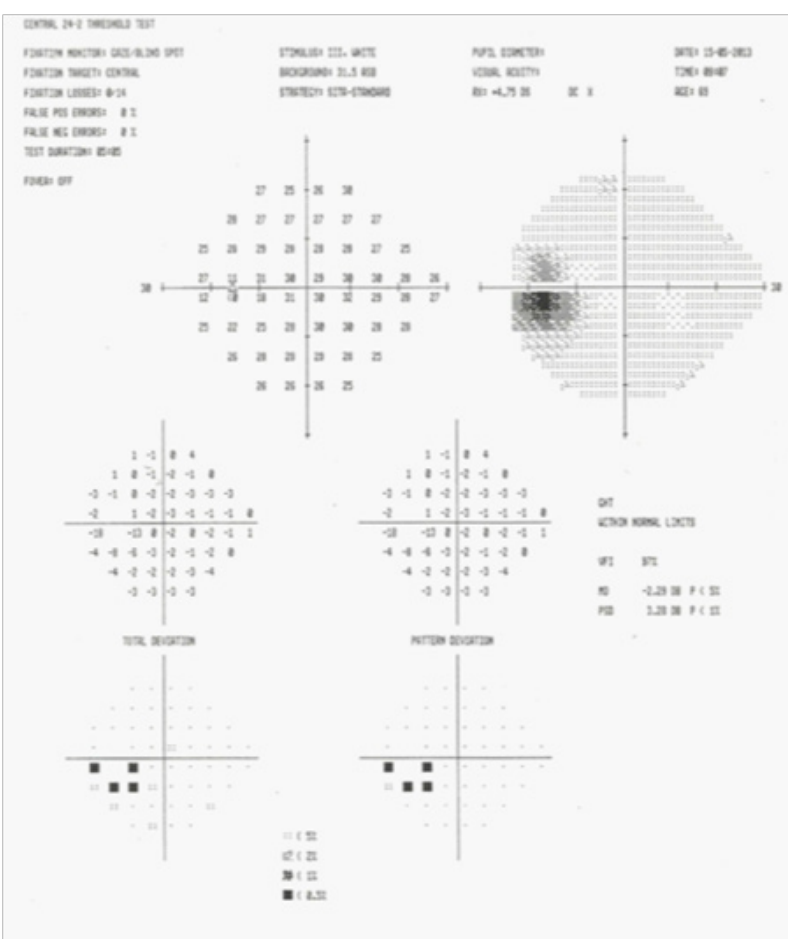

Figure 7 Left eye-Enlarged Blind Spot. 
OCT: (Figures 8\&9).

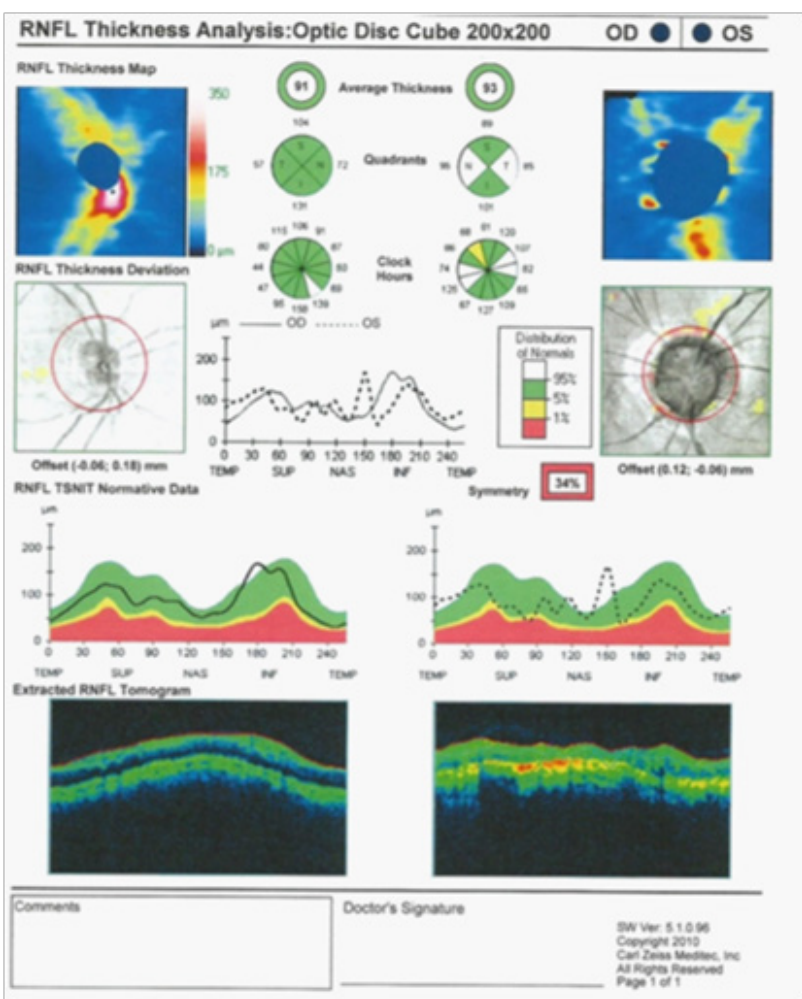

Figure 8 OCT.

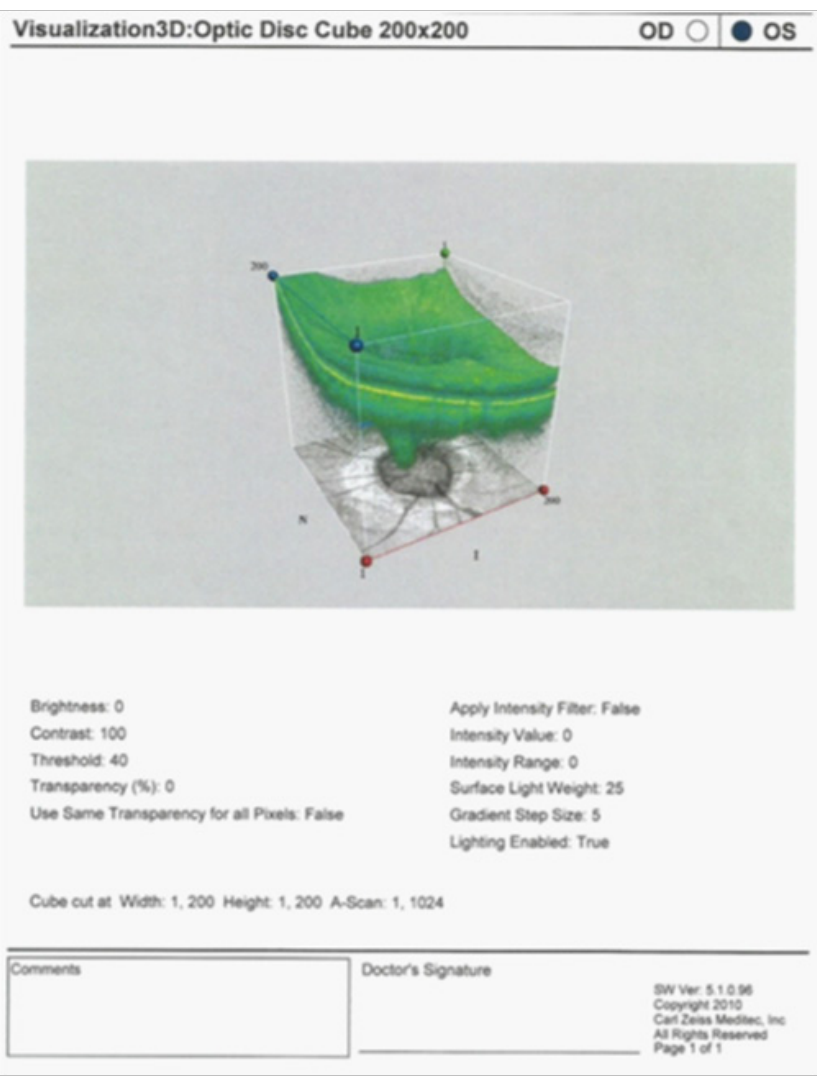

Figure 9 3D OCT.
RE: Normal.

LE: Did not show any evidence of slit like retinal break at the edge of the anomalous disc or a hole in the optic disc on 3D OCT.

\section{Neuroimaging}

The patient did not show any neurologic signs or symptoms therefore neuroimaging was not considered.

\section{Discussion}

Excavated optic disk anomalies, such as morning glory syndrome, peripapillary staphyloma, and optic disk coloboma, are rare. These can significantly impair visual function. ${ }^{3}$ If present alone per sec or when associated with complications. One major complication of MGS is Rhegmatogenous retinal detachment. A slit-like retinal break at the edge of the excavated disc anomaly provides a direct communication between the subretinal space and the vitreous cavity.,10 Retinal reattachment and useful vision has been achieved after a single procedure of vitrectomy and gas tamponade. The other etiology of retinal detachment in MGS is presence of a hole in tissue lying within the optic disc anomaly of the morning glory syndrome which provides a communication for fluid between the subretinal space and the vitreous cavity. Vitreous replacement with silicone oil resulted in the migration of silicone bubbles into the subretinal space. ${ }^{7}$ Our patient had reduced BCVA of 6/9-3 in the left eye, since childhood. However our concern in this patient was to rule out any risk of retinal detachment associated with MGS, and therefore besides other investigations we considered it appropriate to perform a $3 \mathrm{D}$ OCT on her. This showed no evidence to suggest either a retinal break or a hole within the optic disc. We therefore conclude that 3D OCT of the optic nerve head is a valuable investigation in the management of a case of MGS.

\section{Acknowledgments}

None.

\section{Conflicts of interest}

Author declares that there is no conflict of interest.

\section{References}

1. Kindler P. Morning glory syndrome: unusual congenital optic disk anomaly. Am J Ophthalmol. 1970;69(3):376-384.

2. Schneider C, Cayrol D, Arnaud B, et al. [Clinically isolated Morning glory syndrome]. J Fr Ophthalmol. 2002;25(2):178-181.

3. Dutton GN. Congenital disorders of the optic nerve: excavations and hypoplasia. Eye (Lond). 2004;18(11):1038-1048.

4. Brodsky MC. Congenital anomalies of the optic disc. In: Miller NR, Newman NG, editors. Walsh \& Hoyt's Clinical Neuro-ophthalmology 5th ed, Chapter 18, USA: Williams \& Wilkins, Baltimore; 1998. 820 p.

5. Haik BG, Greenstein $\mathrm{SH}$, Smith $\mathrm{ME}$, et al. Retinal detachment in the morning glory anomaly. Ophthalmology. 1984;91(12):1638-1647.

6. Ho CL, Wei LC. Rhegmatogenous retinal detachment in morning glory syndrome pathogenesis and treatment. Int Ophthalmol. 2001;24(1):21-24.

7. Coll GE, Chang S, Flynn TE, Brown GC, et al. Communication between the subretinal space and the vitreous cavity in the morning glory syndrome. Graefes Arch Clin Exp Ophthalmol. 1995;233(7):441-443.

8. Bartz-Schmidt KU, Heimann K. Pathogenesis of retinal detachment associated with morning glory disc. Int Ophthalmol. 1995;19(1):35-38. 
9. Jo YJ, Iwase T, Oveson BC, et al. Retinal detachment in morning glory syndrome with large hole in the excavated disc. Eur $J$ Ophthalmol. 2011;21(6):841-844.

10. Ho TC, Tsai PC, Chen MS, et al. Optical coherence tomography in the detection of retinal break and management of retinal detachment in morning glory syndrome. Acta Ophthalmol Scand. 2006;84(2):225-227.
11. Chang S, Gregory-Roberts E, Chen R. Retinal detachment associated with optic disc colobomas and morning glory syndrome. Eye (Lond). 2012;26(4):494-500. 